\title{
Augmentation of neodymium ions removal from water using two lanthanide-based MOF: ameliorated efficiency by synergistic interaction of two lanthanides
}

\author{
Mahsa Najafi ${ }^{\dagger}$, Ahmad Sadeghi Chevinli*, Varsha Srivastava ${ }^{\star}$, Mika Sillanpääđ \\ $\dagger$ Department of Chemical Engineering, Faculty of Engineering, University of Tehran, Tehran, \\ Iran \\ \$Department of Chemical Engineering, Quchan University of Technology, Quchan, Iran \\ " Department of Green Chemistry, LUT School of Engineering Science, Lappeenranta University \\ of Technology, Sammonkatu 12, FI-50130 Mikkeli, Finland
}

*Email: a.sadeghichevinli@gmail.com 


\section{Supporting information}

\section{Kinetic of Adsorption}

The data obtained in this study were fitted with five common kinetic models described below ${ }^{1}$

Pseudo-first order:

$$
\ln \left(q_{e}-q_{t}\right) / q_{e}=-k_{1} t
$$

Pseudo-second order:

$$
t / q_{t}=1 / h+{ }^{t} / q_{e}, h=k_{2} q_{e}^{2}
$$

Elovich:

$$
q_{t}=\frac{1}{\beta} \ln (\alpha \beta)+\frac{1}{\beta} \ln (t)
$$

Inert Particle Diffusion:

$$
q_{t}=C+K_{D} t^{0.5}
$$

Modified Freundlich:

$$
q_{t}=K C_{0} t^{a}
$$

Where qe $(\mathrm{mg} / \mathrm{g})$ is the equilibrium adsorption capacity of the MOF, $\mathrm{q}_{\mathrm{t}}(\mathrm{mg} / \mathrm{g})$ is the adsorption capacity at time $\mathrm{t}(\mathrm{min}), \mathrm{k}_{1}(1 / \mathrm{min}-1)$ is the rate constant of pseudo-first-order model, $\mathrm{k}_{2}$ (g/min.mg) is the rate constant of the pseudo-second-order model, $\mathrm{K}_{\mathrm{D}}$ is the intraparticle diffusion rate constant $\left(\mathrm{mg} / \mathrm{g} \cdot \mathrm{min}^{0.5}\right), \mathrm{K}$ is the apparent adsorption rate constant (L/g.min), $\mathrm{C}_{0}$ is the initial concentration of $\mathrm{Nd}$ ions, $\alpha$ is the initial rate $(\mathrm{mg} / \mathrm{g} \cdot \mathrm{min})$, and $\beta$ is a chemisorption constant $(\mathrm{g} / \mathrm{mg})$.

The mentioned kinetic models have been applied for evaluation of kinetic study of the process and the plots of fitted models with experimental data are presented in Figure S1-5.

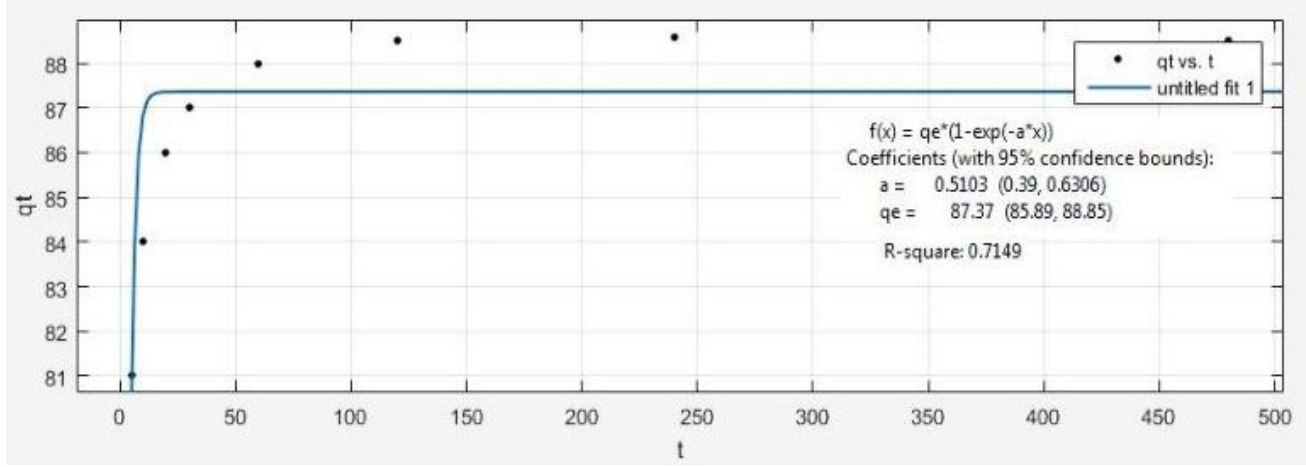

Figure S1. The plot of Pseudo first-order kinetic model 


\section{Supporting information}

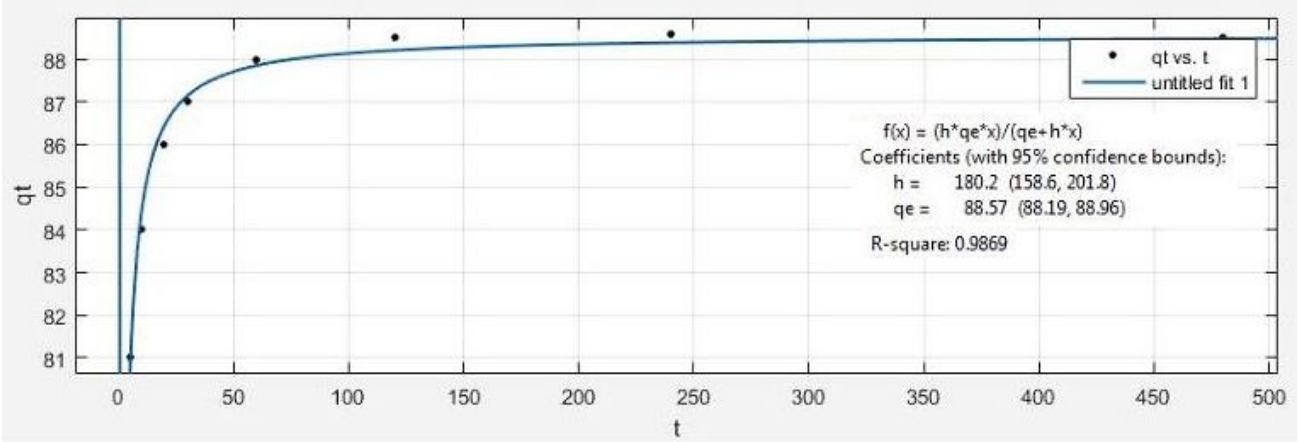

Figure S2. The plot of Pseudo-second order kinetic model

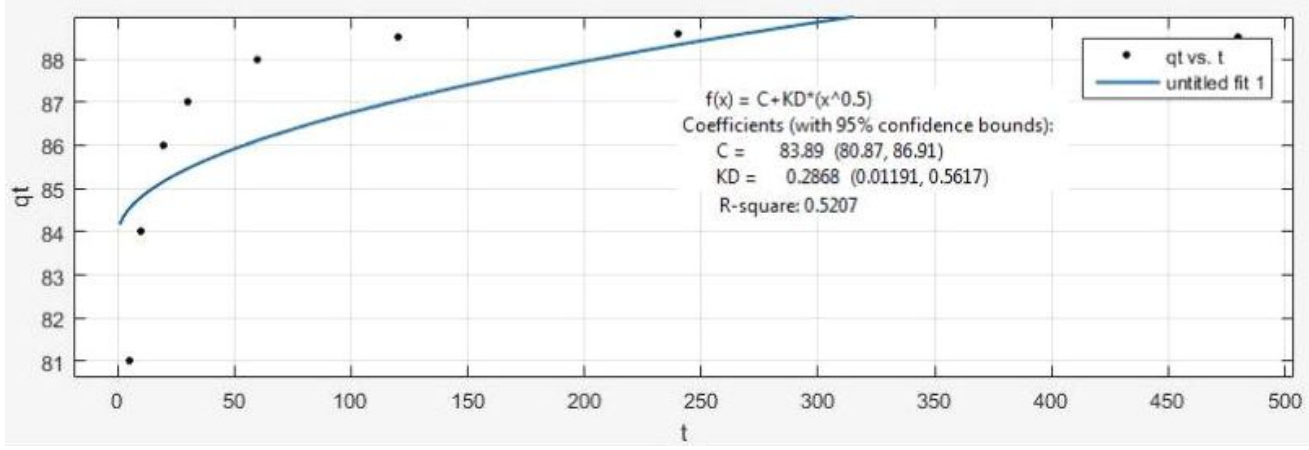

Figure S3. The plot of Intra particle Diffusion kinetic model

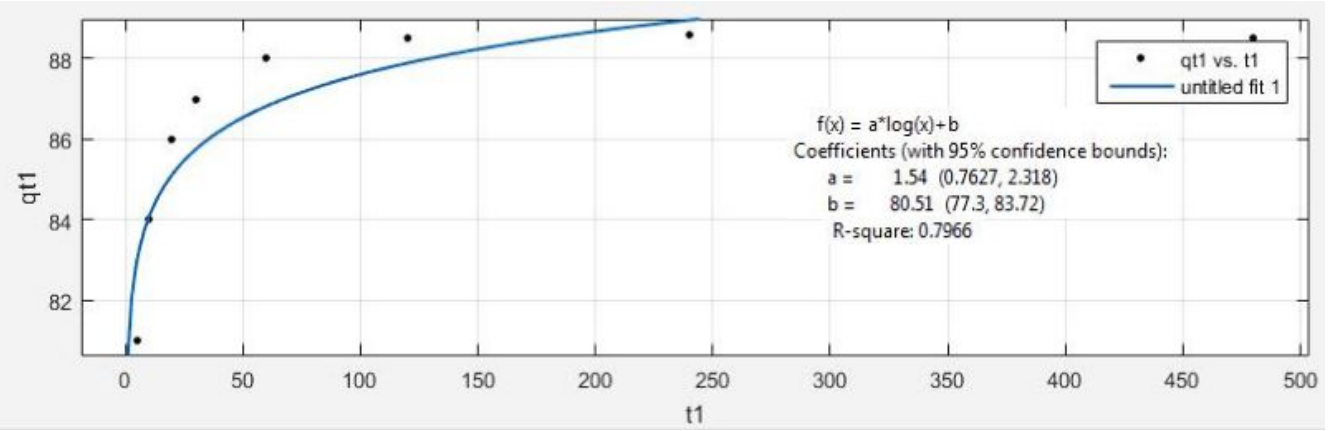

Figure S4. The plot of Elovich kinetic model

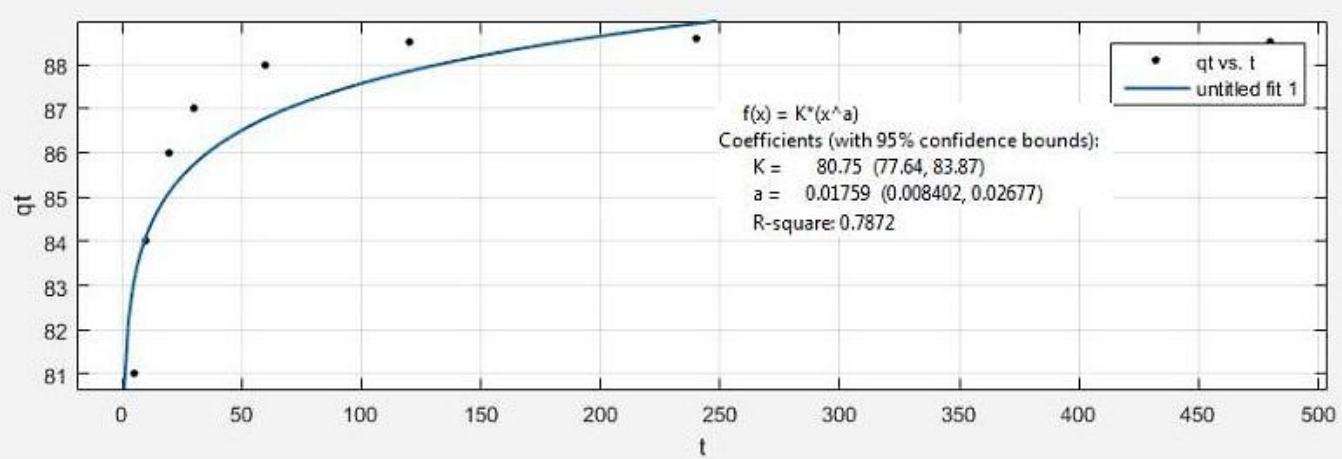

Figure S5. The plot of modified Freundlich kinetic model 


\section{Supporting information}

\section{Isotherm of Adsorption}

The experimental data were plotted with Langmuir, Freundlich, and Tempkin isotherm models. ${ }^{2}$

Langmuir model:

$$
\frac{C_{e}}{q_{e}}=\frac{1}{q_{m}} C_{e}-\frac{1}{K_{L} q_{m}}
$$

Freundlich model:

$$
\ln q_{e}=\ln K_{F}+\left(\frac{1}{n}\right) \ln C_{e}
$$

Tempkin model:

$$
q=\frac{R T}{b_{T}} \ln K_{T} C_{e}
$$

Where $\mathrm{q}_{\mathrm{e}}$ is the equilibrium adsorption capacity of the MOF, $\mathrm{C}_{\mathrm{e}}$ is the concentration of $\mathrm{Nd}$ solution at equilibrium, $\mathrm{q}_{\mathrm{m}}$ is the maximum sorption capacity of the MOF, $\mathrm{K}_{\mathrm{T}}$ is the Langmuir constant $(\mathrm{L} / \mathrm{mg}), \mathrm{KF}_{\mathrm{F}}(\mathrm{L} / \mathrm{g})$ is the Freundlich constant, $1 / \mathrm{n}$ is the heterogeneity factor, $\mathrm{R}$ is the ideal gas constant $(8.314 \mathrm{~J} / \mathrm{mol}$. $\mathrm{K})$, $\mathrm{T}$ is the absolute temperature $(\mathrm{K})$, and $\mathrm{b}$ ( $(\mathrm{J} / \mathrm{mol})$ is heat of adsorption $(\mathrm{J} / \mathrm{mol})$.

Figure S6-8 depict the linear plots of three isotherm models with experimental data.

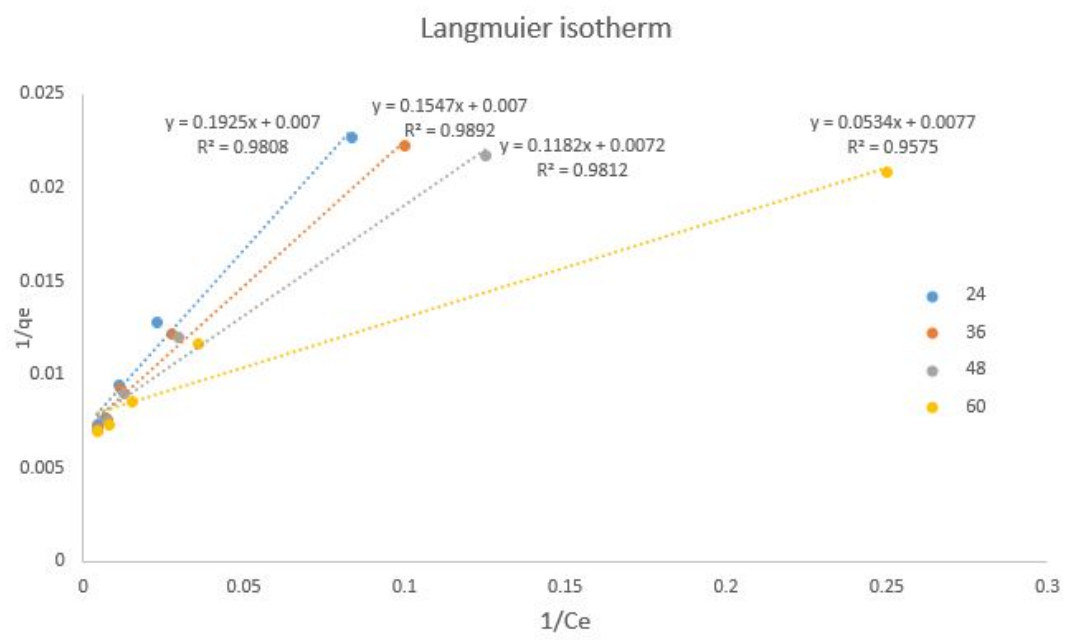

Figure S6. Linear plot of Langmuir isotherm 


\section{Supporting information}

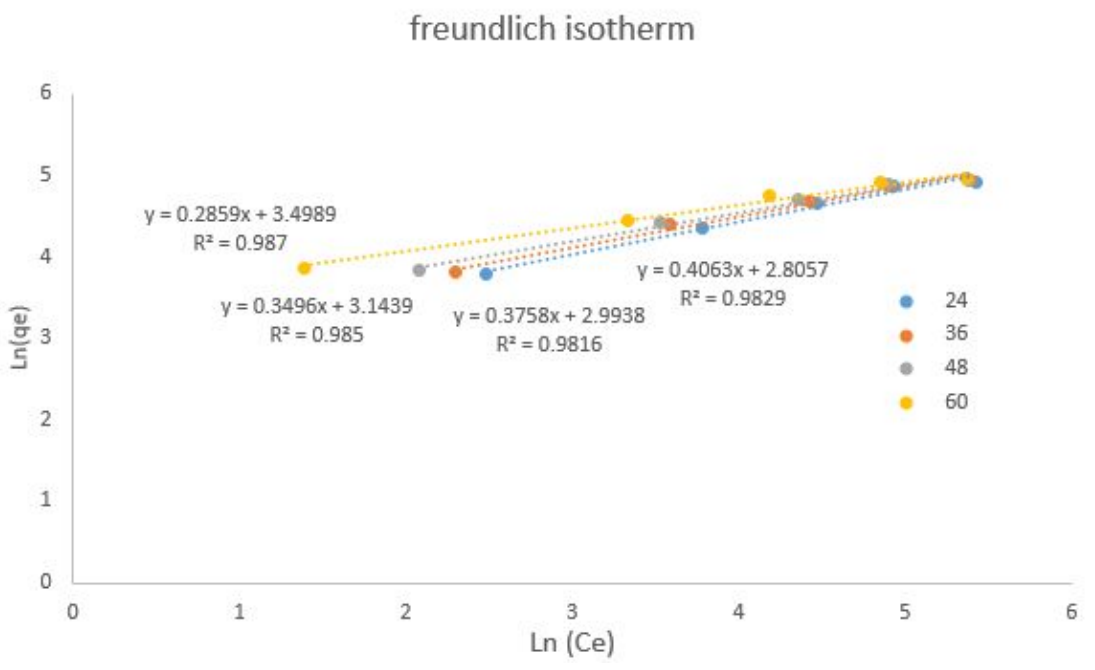

Figure S7. Linear plot of Freundlich isotherm

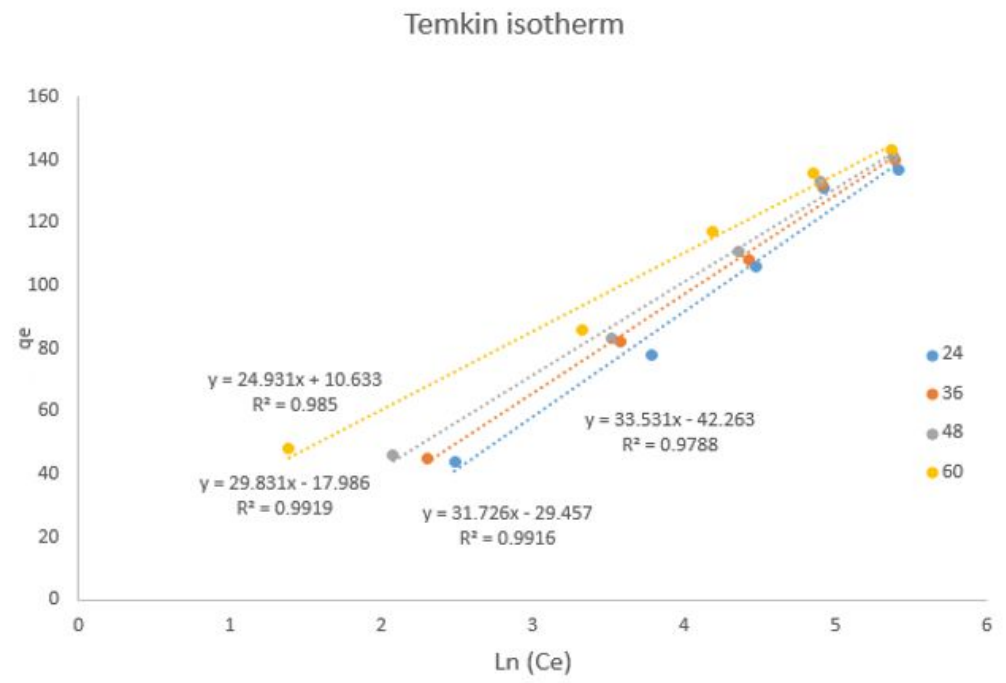

Figure S8. Linear plot of Temkin isotherm

\section{Thermodynamic of Adsorption}

For calculating the thermodynamic parameters, the following equations have been considered. ${ }^{3}$ 


\section{Supporting information}

$$
\begin{gathered}
k=\frac{C_{0}-C_{e}}{C_{e}} \\
\ln (k)=\frac{\Delta S^{\circ}}{R}-\frac{\Delta H^{\circ}}{R T} \\
\Delta G^{\circ}=-R T \ln K
\end{gathered}
$$

where $\mathrm{C}_{0}(\mathrm{mg} / \mathrm{l})$ is the initial concentration of $\mathrm{Nd}$ ions, $\mathrm{Ce}(\mathrm{mg} / \mathrm{l})$ is the equilibrium concentration of $\mathrm{Nd}$ ions, $\Delta \mathrm{H}^{\circ}$ is the average change in standard enthalpy, $\Delta \mathrm{S}^{\circ}$ is the average change in standard entropy, $\Delta G^{\circ}$ is the average of change in standard free energy of sorption, $R$ is the universal gas constant and $\mathrm{K}$ is the equilibrium constant.

The linear plot of Vant Hoff equation based on the experimental data is shown in Figure S9.

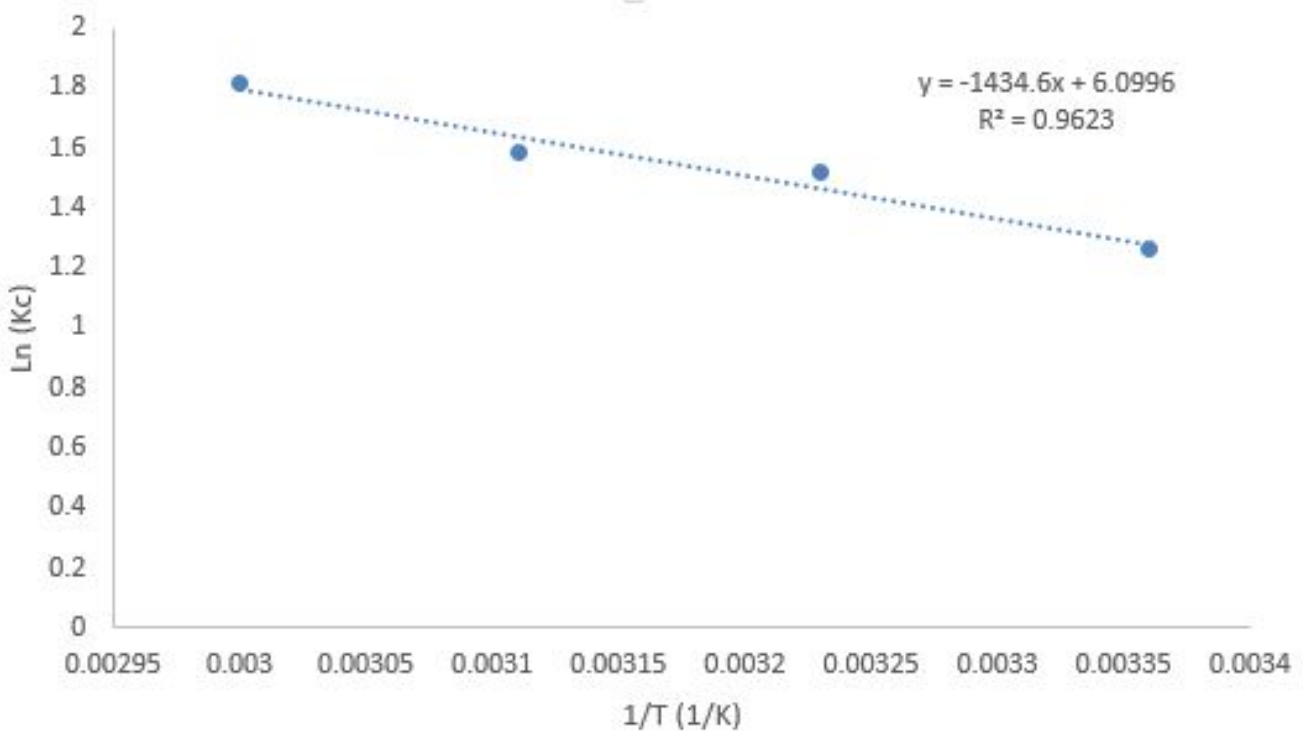

Figure S9. Linear plot of Vant-Hoff equation

\section{REFERENCES:}

1. Onal, Y. Kinetics of adsorption of dyes from aqueous solution using activated carbon 


\section{Supporting information}

prepared from waste apricot. J. Hazard. Mater. 2006, 137, 1719-1728.

2. Saleh, T. A. Isotherm, kinetic, and thermodynamic studies on Hg ( II ) adsorption from aqueous solution by silica- multiwall carbon nanotubes. Environ. Sci. Pollut. Res. 2015, 22, 16721-16731.

3. $\mathrm{Xu}, \mathrm{X}$. et al. Novel high-gluten flour physically cross-linked graphene oxide composites: Hydrothermal fabrication and adsorption properties for rare earth ions. Ecotoxicol. Environ. Saf. 2018, 166, 1-10. 